\title{
An Investigation on the Dynamic Response of Cable Stayed Bridge with Consideration of Three-Axle Vehicle Braking Effects
}

\author{
Xuan-Toan Nguyen, ${ }^{1}$ Van-Duc Tran, ${ }^{2}$ and Nhat-Duc Hoang ${ }^{3}$ \\ ${ }^{1}$ Department of Road and Bridge Construction, Danang University of Science and Technology, Danang, Vietnam \\ ${ }^{2}$ International School, Duy Tan University, Danang, Vietnam \\ ${ }^{3}$ Institute of Research and Development, Faculty of Civil Engineering, Duy Tan University, Danang, Vietnam
}

Correspondence should be addressed to Nhat-Duc Hoang; hoangnhatduc@dtu.edu.vn

Received 21 April 2017; Accepted 14 May 2017; Published 11 June 2017

Academic Editor: Jia-Jang Wu

Copyright (C) 2017 Xuan-Toan Nguyen et al. This is an open access article distributed under the Creative Commons Attribution License, which permits unrestricted use, distribution, and reproduction in any medium, provided the original work is properly cited.

\begin{abstract}
The cable-stayed bridge (CSB) is often used to span over the large rivers on the highway with a high-level navigational clearance; however, CSB is very sensitive to live load. Most of the previous studies on vibration analysis of CSB that focus on complex traffic loading and vehicle dynamic interaction as well as on the bridge deck do not consider braking effects thoroughly. In this paper, the finite element method (FEM) is used to investigate the dynamic response of CSB due to a three-axle vehicle considering braking effects. Vertical reaction forces of axles that change with time make bending vibration of the bridge deck increase significantly. The braking in a span is able to create response in other spans, towers, and cables. In addition, the impact factors are investigated on both FEM and experiment with a case study of Pho Nam bridge (Danang city, Central Vietnam). The results of this study provide an improved understanding of the CSB dynamic behaviors, and they can be used as useful references for bridge codes by practicing engineers.
\end{abstract}

\section{Introduction}

Researchers have studied the response of bridges subjected to vehicles moving since the 50s of the 19th century. Recently, the previous study has analyzed the complex problem of oscillations with the model interaction between vehicle and bridge which is closer to the reality. Most studies focus on the dynamic behavior of bridge subjected to vehicles moving with constant speeds. Only a few research directions towards the dynamic behavior of the bridge under the effect of vehicle with variable velocities (due to many reasons like brakes, incident on the bridge, etc.). Fryba [1] introduced a fundamental study of beam due to mass roll on the train rails considering the braking force effect and also studied the quasi-static distribution of braking. The study of Kishan and Trail-Nash [2] concerned the dynamic response of highway bridges under the effect of vehicle braking force, and the resulting impact factors may be larger than those adopted in the current design code. Gupta and Trail-Nash [3] investigated the dynamic behavior of bridge model with single span uniform beam considering the road surface irregularities and vehicle braking force. Law and Zhu [4] studied the dynamic behavior of continuous three spans under moving vehicle considering braking load and the roughness of the road surface. Ju and Lin [5] and González [6] used FEM to calculate the vertical vibration of beams caused by moving vehicle due to the braking force. Deng and Cai [7] have developed of impact factor for performance evaluation of existing multigirder concrete bridges due to the road surface deterioration of existing bridges. Yin et al. [8] presented a new method of analyzing the non-stationary random response of bridges. Zhang and Xie [9] studied dynamic responses of CSBs under vehicular loads using the FEM, while the local vibration of stay cables is analyzed using the substructure method. Zhou et al. [10] studied the dynamic load allowance calculation methods for bridges according to the dynamic response curve. Deng and Wang [11] developed a model to study the impact factors of simply supported prestressed concrete girder bridges due to vehicle braking with a three-dimensional vehicle-bridge coupled 


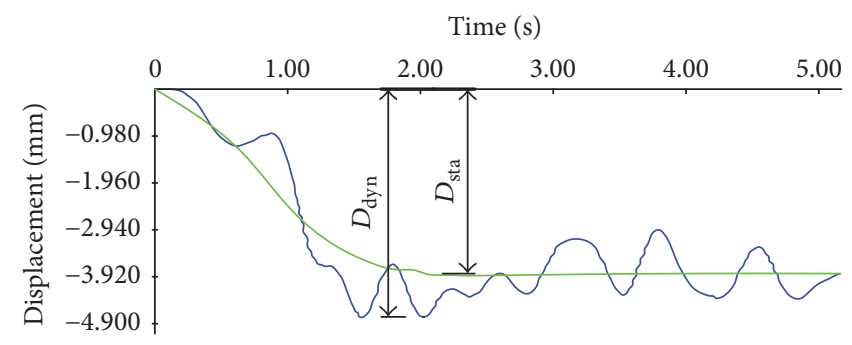

Figure 1: Dynamic and static displacement under a vehicle moving.

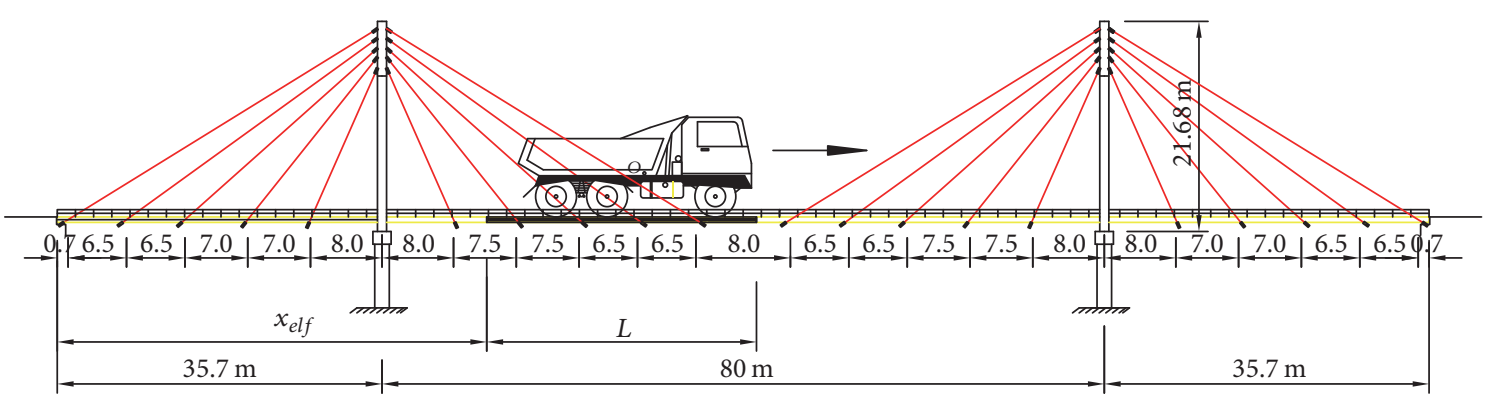

Figure 2: A three-axle vehicle move on the Pho Nam bridge.

model. Toan et al. [12-15] studied the dynamic vibration of a cable-stayed bridge subjected to moving vehicles considering the braking forces and the variable acceleration.

Although some good researches as discussed above can be found in overall bridge dynamics, very few researches have been conducted related to the dynamic interaction in the cable-stayed bridge with considering braking effects. This paper presents the results of the dynamic response of cablestayed bridge subjected to dynamic wheel loads by FEM analysis and experimental investigation. The vibration of the cable-stayed bridge was analyzed with various vehicle speeds considering the braking effects varied to assess the amount of interaction between the vehicle and the cable-stayed bridge.

The main objective of the test is to validate a calculation procedure for determination of the Impact Factor (IF) of cable-stayed bridge to dynamic wheel loads due to vehicle speed and braking effects. There are many definitions for IF or $(1+\mathrm{IM})[16]$; in this paper IF is taken as the ratio of dynamic and static responses:

$$
(1+\mathrm{IM})=\mathrm{IF}=\frac{D_{\text {dynamic }}}{D_{\text {static }}},
$$

where $D_{\text {dynamic }}$ is the absolute maximum dynamic deflection response at any point and $D_{\text {static }}$ is the maximum static response obtained from the filtered dynamic response. An example of bridge response for a vehicle moving on the highway bridge is shown in Figure 1.

\section{Finite Element Method Analysis}

2.1. Computational Models and Assumptions. The cablestayed bridge used in this study is the Pho Nam bridge located in Danang, Vietnam, which is three-span steel cable-stayed bridge with a main span of $80 \mathrm{~m}$ and a side span of $35.7 \mathrm{~m}$. The three-axle vehicle moving on the bridge is shown in Figure 2.

Stayed cables were modeled as cable elements with considering tensional force and deflection of the cables. The tower structures of the cable-stayed bridge were modeled as frame elements which can be found in Zienkiewicz and Taylor [17]. The nonlinear dynamic vibration of cable element in the cable-stayed bridges subjected to moving loads can be found in investigation of Shimada [18]. The girder beams of the cable-stayed bridge were modeled as beam elements which interact directly to the three-axle vehicle. The dynamic interaction between a beam element and three-axle vehicle modeled by the braking forces and acceleration is shown in Figure 3, where

$$
x_{i}= \begin{cases}v_{i} \cdot\left(t-t_{i}\right)-x_{e l f} & \text { if } t_{i} \leq t \leq t_{b i} \\ v_{i} \cdot\left(t_{b i}-t_{i}\right)+\left[\frac{a_{i} \cdot\left(t-t_{b i}\right)}{2}+v_{i}\right] \cdot\left(t-t_{b i}\right)-x_{e l f} & \text { if } t_{b i}<t \leq t_{e i},\end{cases}
$$

where $L$ is the length of the beam element. $x_{o}$ is the coordinate of vehicle mass $m$ at the time $t . x_{i}$ is the coordinate of the $i$ th axle at the time $t(i=1,2,3) . x_{\text {elf }}$ is the distance from the left end of bridge to the left end of beam element. $v_{i}$ is 


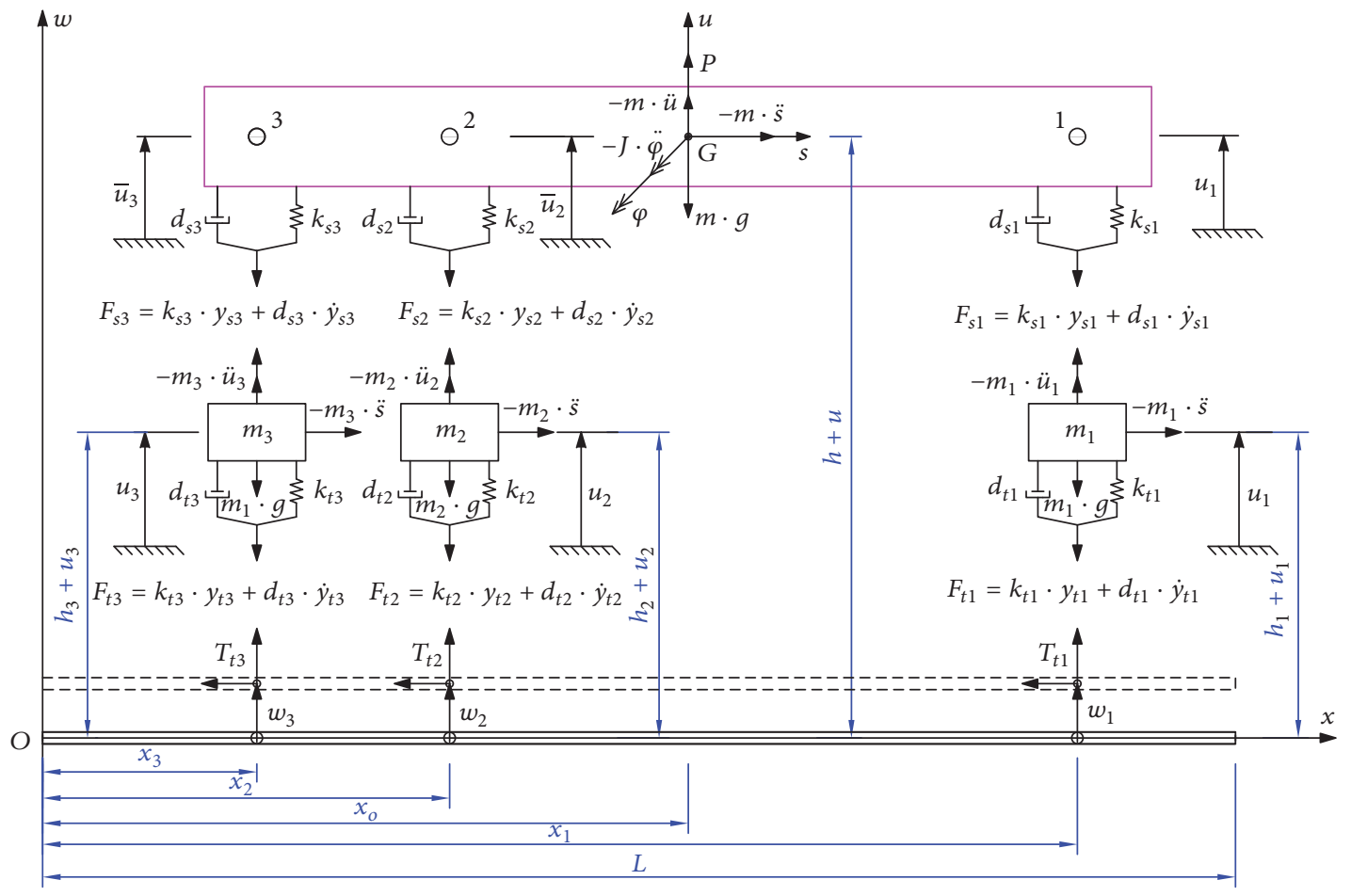

FIgURE 3: The dynamic interaction model between a three-axle vehicle and beam element.

the velocity of the $i$ th axle before the vehicle brakes. $a_{i}$ is the acceleration of the $i$ th axle when brake is used $\left(a_{i}<0\right) . t$ is the time at current location. $t_{i}$ is the time when the $i$ th axle begins entering the bridge. $t_{b i}$ is the time when vehicle brakes on the $i$ th axle. $t_{e i}$ is the time when the $i$ th axle stops. $P=$ $G \cdot \sin (\Omega \cdot t+\alpha)$ is the stimulating force caused by the eccentric mass of engine. $m$ is the mass of vehicle and goods, excluding the mass of the axles. $m_{1}, m_{2}$, and $m_{3}$ are the masses of the 1 st, 2 nd, 3rd axle, respectively. $k_{s 1}, k_{s 2}, k_{s 3}, d_{s 1}, d_{s 2}$, and $d_{s 3}$ are the stiffness and the damping of the three axles. $k_{t 1}, k_{t 2}, k_{t 3}$, $d_{t 1}, d_{t 2}$, and $d_{t 3}$ are the stiffness and the damping of the three tires. $\ddot{s}$ is the acceleration of vehicle. $\varphi$ is the rotational angle of chassis. $u$ is the vertical displacement of the chassis center. $\bar{u}_{1}, \bar{u}_{2}$, and $\bar{u}_{3}$ are the vertical displacements of chassis at the three axles. $u_{1}, u_{2}$, and $u_{3}$ are the vertical displacements of the three axles. $y_{s 1}, y_{s 2}$, and $y_{s 3}$ are the relative displacements between the chassis and the three axles. $y_{t 1}, y_{t 2}$, and $y_{t 3}$ are the relative displacements between the beam element and the three axles. $h_{1}, h_{2}$, and $h_{3}$ are the heights from the center of beam element to centers of mass $m_{1}, m_{2}$, and $m_{3} . T_{t 1}$, $T_{t 2}$, and $T_{t 3}$ are the friction forces between tire and bridge surface.

Inertial forces, damping forces, elastic forces, stimulating forces, and braking forces of system are shown in Figure 3.

The following assumptions are adopted:

The mass of the vehicle, excluding the mass of the axles, is transferred to the mass center of the system. It is equivalent to the mass $m$ and rotational inertia $J$.

The mass of the 1st axle is $m_{1}$, which is considered as a mass point at the center of the corresponding axle. Similarly, the masses of the 2nd and 3rd axles are $m_{2}$ and $m_{3}$.
The chassis is assumed to be absolutely rigid. The materials of beam are linear elastic stage. The bridge surface has the homogeneous friction coefficient over the entire bridge surface.

Braking forces of the axles of vehicle are assumed to occur simultaneously. The forces direction between bridge surface and tires is assumed to be in the opposite direction of the moving vehicle as shown in Figure 3.

When the vehicle is suddenly braked, the friction forces $T_{t 1}, T_{t 2}$, and $T_{t 3}$ are assumed to be directly proportional the weight of vehicle.

$$
T_{t 1}+T_{t 2}+T_{t 3}=\left(m+m_{1}+m_{2}+m_{3}\right) \cdot g \cdot \tau,
$$

where $\tau$ is the coefficient of friction between the tire and the bridge surface; $g$ is the acceleration of gravity.

\subsection{Vibration of Beam Elements due to Braking Applied} on Three-Axle Vehicle. Based on the calculation model and assumptions in Section 2, the systems of masses $m, m_{1}$, $m_{2}$, and $m_{3}$, inertial forces, damping forces, elastic forces, stimulating force, and braking forces are taken into account. In this case, braking forces are converted to friction forces $T_{t 1}$, $T_{t 2}$, and $T_{t 3}$ as shown in Figure 3. Then we can obtain a set of equations as follows:

$$
\begin{array}{r}
J \cdot \ddot{\varphi}+\sum_{i=1}^{n} d_{s i}\left(x_{i}-x_{o}\right)^{2} \cdot \dot{\varphi}+\sum_{i=1}^{n} d_{s i}\left(x_{i}-x_{o}\right) \cdot \dot{u} \\
-\sum_{i=1}^{n} d_{s i}\left(x_{i}-x_{o}\right) \cdot \dot{u}_{i}+\sum_{i=1}^{n} k_{s i}\left(x_{i}-x_{o}\right)^{2} \cdot \varphi
\end{array}
$$




$$
\begin{aligned}
&+\left[\sum_{i=1}^{n} k_{s i}\left(x_{i}-x_{o}\right)-m \cdot \ddot{s}\right] \cdot u \\
&-\sum_{i=1}^{n}\left[k_{s i}\left(x_{i}-x_{o}\right)+m_{i} \cdot \ddot{s}\right] \cdot u_{i}-\sum_{i=1}^{n} T_{t i} \cdot w_{i} \\
&-\left(m \cdot h+\sum_{i=1}^{n} m_{i} \cdot h_{i}\right) \cdot \ddot{s}=0 \\
& m \cdot \ddot{u}+\sum_{i=1}^{n} d_{s i}\left(x_{i}-x_{o}\right) \cdot \dot{\varphi}+\sum_{i=1}^{n} d_{s i} \cdot \dot{u}-\sum_{i=1}^{n} d_{s i} \cdot \dot{u}_{i} \\
&+\sum_{i=1}^{n} k_{s i}\left(x_{i}-x_{o}\right) \cdot \varphi+\sum_{i=1}^{n} k_{s i} \cdot u-\sum_{i=1}^{n} k_{s i} \cdot u_{i}-P \\
&+m \cdot g=0 \\
& m_{i} \cdot \ddot{u}_{i}-d_{s i}\left(x_{i}-x_{o}\right) \cdot \dot{\varphi}-d_{s i} \cdot \dot{u}+\left(d_{s i}+d_{t i}\right) \cdot \dot{u}_{i} \\
& \quad-k_{s i}\left(x_{i}-x_{o}\right) \cdot \varphi-k_{s i} \cdot u+\left(k_{s i}+k_{t i}\right) \cdot u_{i}-d_{t i} \cdot \dot{w}_{i} \\
& \quad-k_{t i} \cdot w_{i}+m_{i} \cdot g=0 \\
& \ddot{s}=-g \cdot \tau .
\end{aligned}
$$

According to the study Ray and Joseph [19], the differential equation of motion for the flexure vibration of damped beam due to uniform loading $p(x, z, t)$ can be written as follows:

$$
\begin{aligned}
E J_{d} & \cdot\left(\frac{\partial^{4} w}{\partial x^{4}}+\theta \cdot \frac{\partial^{5} w}{\partial x^{4} \cdot \partial t}\right)+\rho F_{d} \cdot \frac{\partial^{2} w}{\partial t^{2}}+\beta \cdot \frac{\partial w}{\partial t} \\
\quad= & \sum_{i=1}^{n} p_{i}(x, z, t) .
\end{aligned}
$$

The differential equation of longitudinal motion for a beam element due to uniform loading $q(x, z, t)$ can be written as follows:

$$
\begin{aligned}
& E F_{d} \cdot \frac{\partial^{2} u_{x}}{\partial x^{4}}+\rho F_{d} \cdot \frac{\partial^{2} u_{x}}{\partial t^{2}}+\beta \cdot \frac{\partial u_{x}}{\partial t}=q(x, z, t) \\
& \quad=\tau \cdot \sum_{i=1}^{n} p_{i}(x, z, t),
\end{aligned}
$$

where $F_{d}$ is the cross-sectional area; $J_{d}$ is the second moment of area; $E$ is Young's modulus; $E J_{d}$ is the flexural rigidity of the beam element; $E F_{d}$ is the axial rigidity of the beam element; $\rho F_{d}$ is the mass of beam per unit length; $\theta$ and $\beta$ are the coefficients of internal friction and external friction; $u_{x}$ is the axial displacement of the beam element.

$$
\begin{gathered}
p_{i}(x, z, t)=\xi\left(x_{i}\right) \cdot F_{t i} \cdot \delta\left(x-x_{i}\right)=\xi\left(x_{i}\right) \cdot\left[-m_{i} \cdot \ddot{u}_{i}\right. \\
+d_{s i}\left(x_{i}-x_{o}\right) \cdot \dot{\varphi}+d_{s i} \cdot \dot{u}-d_{s i} \cdot \dot{u}_{i}+k_{s i}\left(x_{i}-x_{o}\right) \\
\left.\cdot \varphi+k_{s i} \cdot u-k_{s i} \cdot u_{i}-m_{i} \cdot g\right] \cdot \delta\left(x-x_{i}\right),
\end{gathered}
$$

where $\delta\left(x-x_{i}\right)$ is the Dirac delta function;

$$
\xi\left(x_{i}\right)= \begin{cases}1 & \text { if } 0 \leq x_{i} \leq L \\ 0 & \text { if } x_{i}<0 \text { and } x_{i}>L\end{cases}
$$

is the logic control signal function.

The Galerkin method and Green theory are applied to (4), (5), (6), and (7) to transform these equations into matrix forms, and the differential equations of beam element can be written as follows:

$$
M_{e} \cdot \ddot{q}+C_{e} \cdot \dot{q}+K_{e} \cdot q=f_{e}
$$

$\ddot{q}, \dot{q}, q$, and $f_{e}$ are the complex acceleration vector, complex velocity vector, complex displacement vector, complex forces vector, respectively.

$$
\begin{gathered}
\ddot{q}=\left\{\begin{array}{c}
\ddot{w}_{e} \\
\ddot{z}
\end{array}\right\} ; \\
\dot{q}=\left\{\begin{array}{c}
\dot{w}_{e} \\
\dot{z}
\end{array}\right\} ; \\
q=\left\{\begin{array}{c}
w_{e} \\
z
\end{array}\right\} ; \\
f_{e}=\left\{\begin{array}{c}
f_{w} \\
f_{z}
\end{array}\right\} ; \\
w_{e}=\left\{\begin{array}{c}
u_{x 1} \\
w_{y 1} \\
\varphi_{1} \\
u_{x 2} \\
w_{y 2} \\
\varphi_{2}
\end{array}\right\} ; \\
z=\left\{\begin{array}{c}
\varphi \\
u \\
u_{1} \\
\vdots \\
u_{n}
\end{array}\right\},
\end{gathered}
$$

where $u_{x 1}, w_{y 1}$, and $\varphi_{1}$ are the axial displacement, flexural deflection, and rotation angle of the left end of element, respectively; $u_{x 2}, w_{y 2}$, and $\varphi_{2}$ are the axial displacement, flexural deflection, and rotation angle of the right end of element, respectively; $M_{e}, C_{e}$, and $K_{e}$ are the mass matrix, damping matrix, and stiffness matrix, respectively.

$$
M_{e}=\left[\begin{array}{cc}
M_{w w} & M_{w z} \\
M_{z w} & M_{z z}
\end{array}\right]
$$




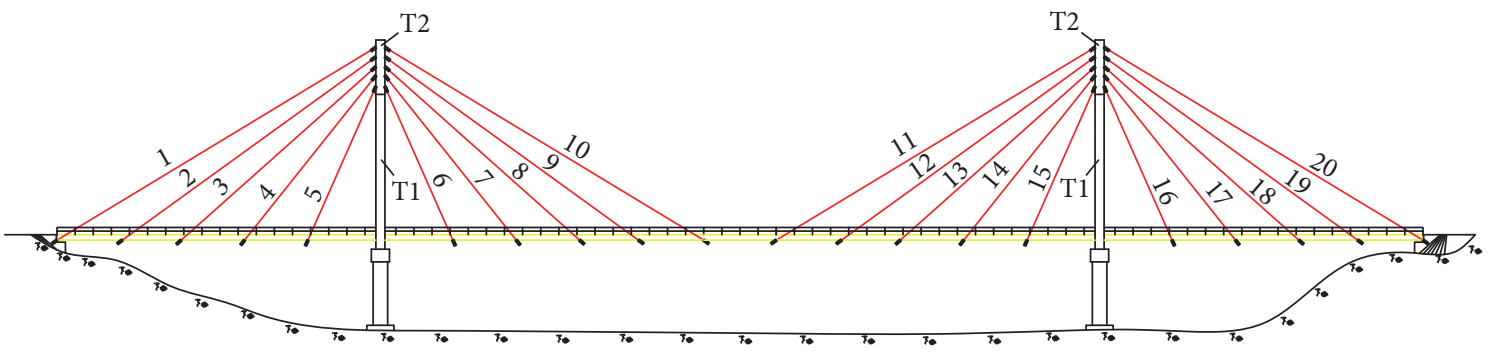

Figure 4: The cables plane of the Pho Nam bridge.

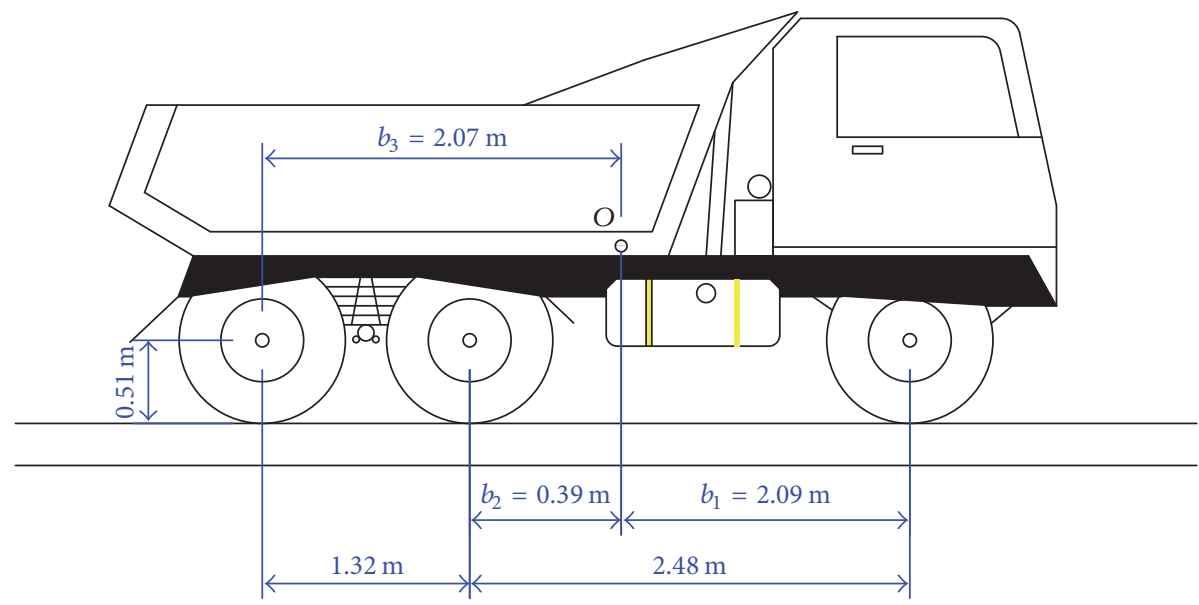

FIgURE 5: The three-axle vehicle dimensional parameters.

$$
\begin{aligned}
C_{e} & =\left[\begin{array}{ll}
C_{w w} & C_{w z} \\
C_{z w} & C_{z z}
\end{array}\right] ; \\
K_{e} & =\left[\begin{array}{ll}
K_{w w} & K_{w z} \\
K_{z w} & K_{z z}
\end{array}\right],
\end{aligned}
$$

where $M_{w w}, C_{w w}$, and $K_{w w}$ are mass, damping, and stiffness matrices of the beam element which can be found in Zienkiewicz and Taylor [17]. $M_{w z}, M_{z w}, M_{z z}, C_{w z}, C_{z w}, C_{z z}$, $K_{w z}, K_{z w}$, and $K_{z z}$ are mass, damping, and stiffness matrices of interaction between beam element and vehicle subjected to moving loads which can be found in previous study of Toan and Duc [12].

2.3. Analysis of the Dynamic Vibration of the Pho Nam Bridge in Danang City by the FEM. Apply the FEM and the algorithm of the FEM can be found in Zienkiewicz and Taylor [17]; we have the dynamic vibration differential equation for the system as in

$$
M \cdot \ddot{Q}+C \cdot \dot{Q}+K \cdot Q=F,
$$

in which $M, K$, and $C$ are the mass matrix, damping matrix, and stiffness matrix of system; $\ddot{Q}, \dot{Q}, Q$, and $F$ are the acceleration vector, the velocity vector, the deflection vector, and the force vector of the system.

After imposing boundary and initial conditions on (12), we can solve this equation by the Runge-Kutta-Merson method. The numerical values of the vehicle and bridge parameters were used in the computer simulation as follows.

The Cable Properties (Figure 4). Consider cross-sectional area of cables number $4,5,6,7,14,15,16$, and 17: $A_{c}=980 \mathrm{~mm}^{2}$; number $2,3,8,9,12,13,18$, and 19: $A_{c}=1260 \mathrm{~mm}^{2}$; No. 1, 10, 11, 20: $A_{c}=1680 \mathrm{~mm}^{2}$.

The Girder Properties. $E=2.1 \times 10^{9} \mathrm{kN} / \mathrm{m}^{2}, J_{d}=0.001702 \mathrm{~m}^{4}$, $F_{d}=0.02568 \mathrm{~m}^{2}, q_{y}=\rho F_{d}=20.35 \mathrm{kN} / \mathrm{m}, \theta=0.027$, and $\beta=0.01, g=9,81 \mathrm{~m} / \mathrm{s}^{2}, \tau=0.25$.

The Tower Properties (Figure 4). Consider the part T1: $E=2.1$ $\times 10^{9} \mathrm{kN} / \mathrm{m}^{2}, J_{d}=0.00598036 \mathrm{~m}^{4}, F_{d}=0.04706 \mathrm{~m}^{2}$, and $q_{x}=$ $4.06 \mathrm{kN} / \mathrm{m}$.

Consider the part T2: $E=2.1 \times 10^{9} \mathrm{kN} / \mathrm{m}^{2}, J_{d}=$ $0.00439952 \mathrm{~m}^{4}, F_{d}=0.0346 \mathrm{~m}^{2}$, and $q_{x}=4.06 \mathrm{kN} / \mathrm{m}$.

The three-axle vehicle used in the FEM investigation is KAMAZ-55111 (Russia) dumper truck as shown in Figure 5. The three-axle vehicle parameters are $m=85.6 \mathrm{kN}, m_{1}=$ $0.6 \mathrm{kN}, m_{2}=1.1 \mathrm{kN}, m_{3}=1.1 \mathrm{kN}, P=0, b_{1}=2.09 \mathrm{~m}, b_{2}=$ $0.39 \mathrm{~m}, b_{3}=2.07 \mathrm{~m}, h=0.95 \mathrm{~m}, h_{1}=h_{2}=h_{3}=0.51 \mathrm{~m}$, $k_{1 s}=1200 \mathrm{kN} / \mathrm{m}, k_{1 t}=2200 \mathrm{kN} / \mathrm{m}, k_{2 s}=k_{3 s}=1600 \mathrm{kN} / \mathrm{m}$, $k_{2 t}=k_{3 t}=3200 \mathrm{kN} / \mathrm{m}, d_{1 s}=7.34 \mathrm{kNs} / \mathrm{m}, d_{1 t}=3.67 \mathrm{kNs} / \mathrm{m}$, $d_{2 s}=d_{3 s}=4.0 \mathrm{kNs} / \mathrm{m}$, and $d_{2 t}=d_{3 t}=8.0 \mathrm{kNs} / \mathrm{m}$.

The $(1+\mathrm{IM})$ or IFs are evaluated at various points at nodes $4,7,8,9,24,29,39$, and 40 (as shown in Figure 6) in terms of vertical deflections for vehicle speeds of $18 \mathrm{~km} / \mathrm{h}, 36 \mathrm{~km} / \mathrm{h}$, $54 \mathrm{~km} / \mathrm{h}$, and $72 \mathrm{~km} / \mathrm{h}$ with sudden braking shown in Figures $7-10$. 


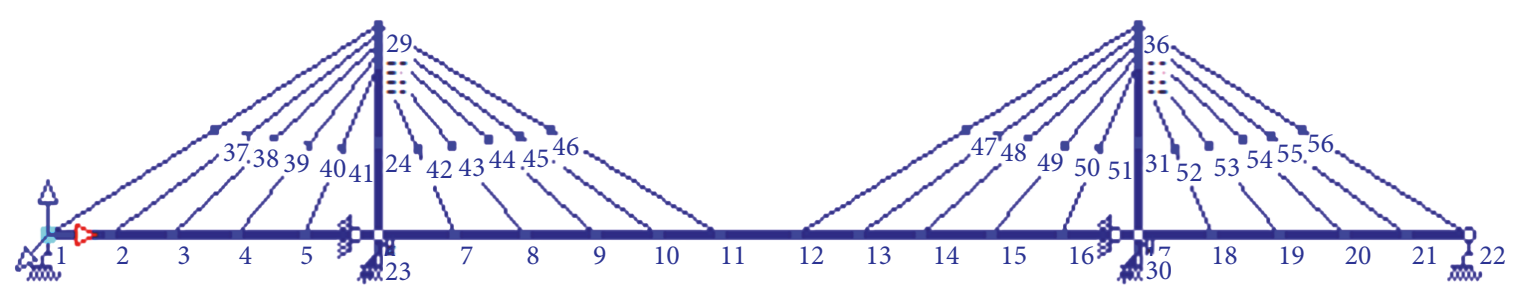

Figure 6: The FEM model of the Pho Nam bridge.

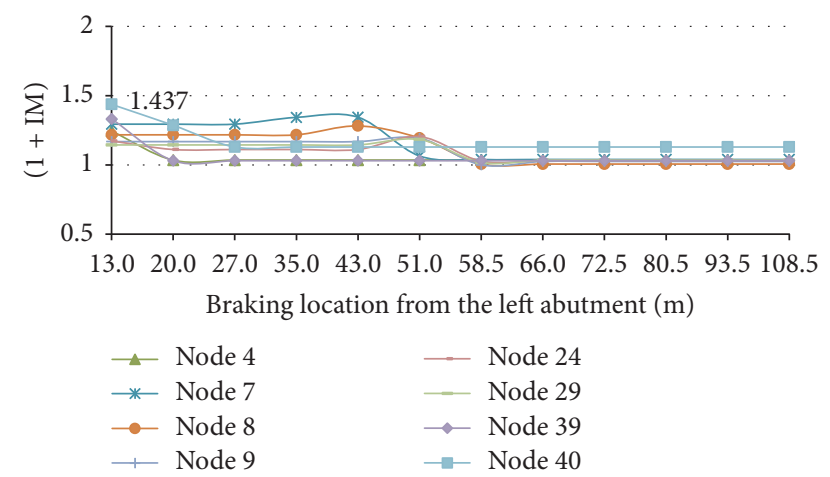

FIGURE 7: Variation of IF in terms of vertical deflections at $18 \mathrm{~km} / \mathrm{h}$ vehicle speed considering braking.

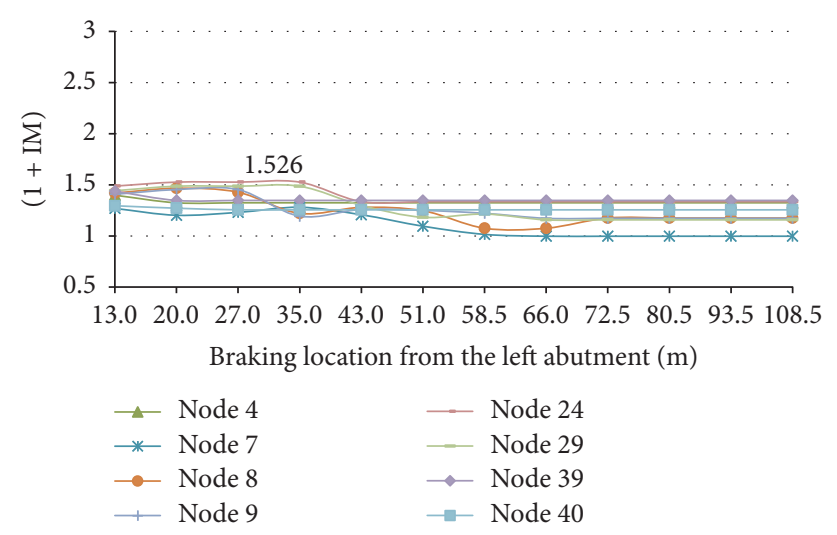

FIGURE 8: Variation of IF in terms of vertical deflections at $36 \mathrm{~km} / \mathrm{h}$ vehicle speed considering braking.

Figure 7 shows the maximum of IF in terms of vertical displacements at $18 \mathrm{~km} / \mathrm{h}$ vehicle speed and braking location from the left abutment at $13 \mathrm{~m}$ is 1.437 for the cable. The IFs in terms of vertical deflections increase with braking effect varying from $0 \%$ to $29.36 \%$ and the average increment of the IFs is $22.61 \%$ at vehicle speed of $18 \mathrm{~km} / \mathrm{h}$.

Figure 8 shows the maximum of IF in terms of vertical displacements at $36 \mathrm{~km} / \mathrm{h}$ vehicle speed and braking location from the left abutment at $20 \mathrm{~m}$ is 1.526 for the tower. The IFs increase with braking effect varying from $3.19 \%$ to $28.44 \%$ and the average increment of the IFs is $16.92 \%$ at vehicle speed of $36 \mathrm{~km} / \mathrm{h}$.

Figure 9 shows the maximum of IF in terms of vertical displacements at $54 \mathrm{~km} / \mathrm{h}$ vehicle speed and braking location

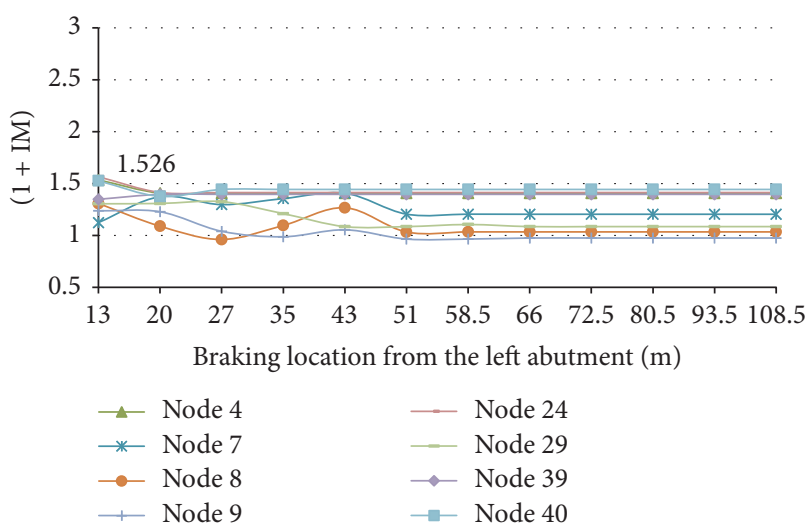

FIGURE 9: Variation of IF in terms of vertical deflections at $54 \mathrm{~km} / \mathrm{h}$ vehicle speed considering braking.

from the left abutment at $13 \mathrm{~m}$ is 1.565 for the tower. The IFs in terms of vertical deflections increase with braking effect varying from $0 \%$ to $26.87 \%$ and the average increment of the IFs is $14.74 \%$ at vehicle speed of $54 \mathrm{~km} / \mathrm{h}$.

Figure 10 shows the maximum of IF in terms of vertical displacements at $54 \mathrm{~km} / \mathrm{h}$ vehicle speed and braking location from the left abutment at $13 \mathrm{~m}$ is 2.064 for the cable. The IFs increase with the braking effect varying from $1.23 \%$ to $29.7 \%$ and the average increment of the IFs is $11.9 \%$ at vehicle speed of $72 \mathrm{~km} / \mathrm{h}$.

The IFs are evaluated at various points at nodes $4,7,8,9$, $24,29,39$, and 40 in terms of axial displacement for vehicle speeds of $18 \mathrm{~km} / \mathrm{h}, 36 \mathrm{~km} / \mathrm{h}, 54 \mathrm{~km} / \mathrm{h}$, and $72 \mathrm{~km} / \mathrm{h}$ and used sudden braking that are shown in Figures 11-14.

Figure 11 shows the maximum of IF in terms of axial displacements at $18 \mathrm{~km} / \mathrm{h}$ vehicle speed and braking location from the left abutment at $13 \mathrm{~m}$ is 1.437 . The IFs in terms of axial displacements increase with the braking effect varying from $0 \%$ to $29.5 \%$ and the average increment of the IFs is $20.8 \%$ at vehicle speed of $18 \mathrm{~km} / \mathrm{h}$.

Figure 12 shows the maximum of IF in terms of axial displacements at $36 \mathrm{~km} / \mathrm{h}$ vehicle speed and braking location from the left abutment at $13 \mathrm{~m}$ is 1.566 for the tower. The IFs in terms of axial displacements increase with the braking effect varying from $0 \%$ to $28.08 \%$ and the average increment of the IFs is $20.1 \%$ at the vehicle speed of $36 \mathrm{~km} / \mathrm{h}$.

Figure 13 shows the maximum of IF in terms of axial displacements at $54 \mathrm{~km} / \mathrm{h}$ vehicle speed and braking location from the left abutment at $20 \mathrm{~m}$ is 1.425 for the tower. The IFs in terms of axial displacements increase with the braking effect 


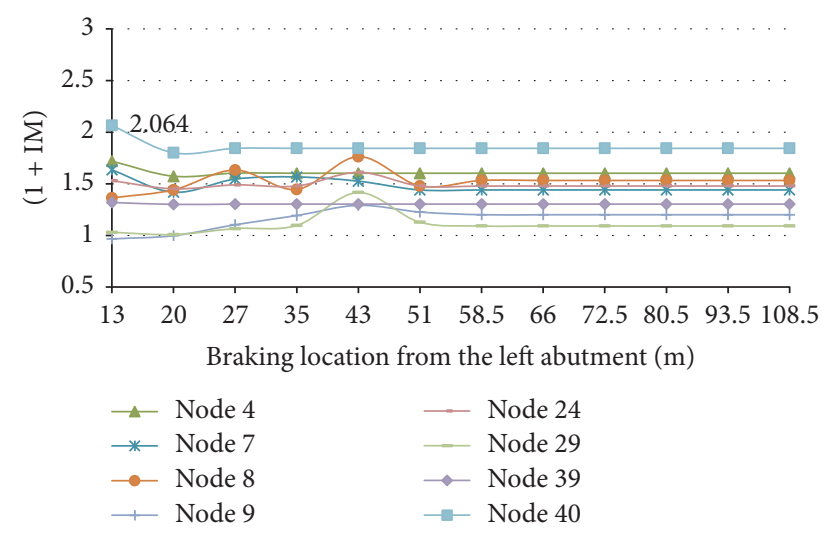

FIGURE 10: Variation of IF in terms of vertical deflections at $72 \mathrm{~km} / \mathrm{h}$ vehicle speed considering braking.

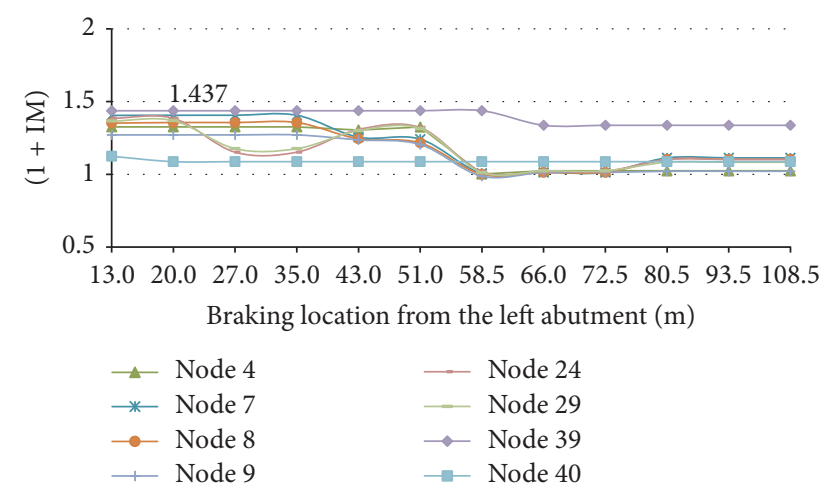

FIGURE 11: Variation of IF in terms of axial displacements at $18 \mathrm{~km} / \mathrm{h}$ vehicle speed considering braking.

varying from $0 \%$ to $29.23 \%$ and the average increment of the IFs is $16.96 \%$ at vehicle speed of $54 \mathrm{~km} / \mathrm{h}$.

Figure 14 shows the maximum of IF in terms of axial displacements at $72 \mathrm{~km} / \mathrm{h}$ vehicle speed and braking location from the left abutment at $43 \mathrm{~m}$ is 1.659 for the tower. The IFs in terms of axial displacements increase with the braking effect varying from $1.6 \%$ to $22.08 \%$ and the average increment of the IFs is $13.9 \%$ at $72 \mathrm{~km} / \mathrm{h}$.

The IFs are evaluated at various points at nodes $4,7,8,9$, $24,29,39$, and 40 in terms of rotation angle for vehicle speeds of $18 \mathrm{~km} / \mathrm{h}, 36 \mathrm{~km} / \mathrm{h}, 54 \mathrm{~km} / \mathrm{h}$, and $72 \mathrm{~km} / \mathrm{h}$ and the results in cases of sudden brakes are used that are shown in Figures 14-17.

Figure 15 shows the maximum of IF in terms of angular displacements at $18 \mathrm{~km} / \mathrm{h}$ vehicle speed and braking location from the left abutment at $43 \mathrm{~m}$ is 1.423 for the span. The IFs in terms of angular displacements increase with braking effect varying from $1.5 \%$ to $28.31 \%$ and the average increment of the IFs is $21.36 \%$ at vehicle speed of $18 \mathrm{~km} / \mathrm{h}$.

Figure 16 shows the maximum of IF in terms of angular displacements at $36 \mathrm{~km} / \mathrm{h}$ vehicle speed and braking location from the left abutment at $13 \mathrm{~m}$ is 1.52 for the tower. The IFs in terms of angular displacements increase with braking effect varying from $0 \%$ to $28.57 \%$ and the average increment of the IFs is $17.32 \%$ at vehicle speed of $36 \mathrm{~km} / \mathrm{h}$.

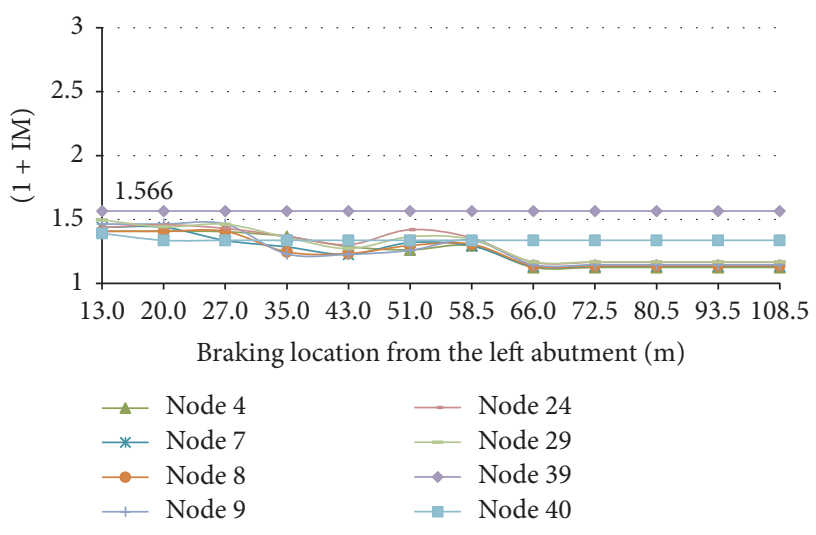

FIGURE 12: Variation of IF in terms of axial displacements at $36 \mathrm{~km} / \mathrm{h}$ vehicle speed considering braking.

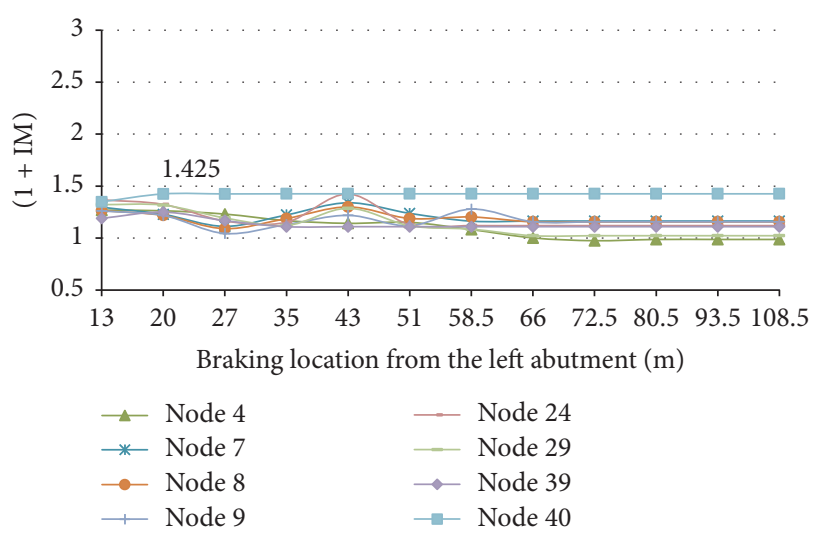

FIGURE 13: Variation of IF in terms of axial displacements at $54 \mathrm{~km} / \mathrm{h}$ vehicle speed considering braking.

Figure 17 shows the maximum of IF in terms of angular displacements at $54 \mathrm{~km} / \mathrm{h}$ vehicle speed and braking location from the left abutment at $13 \mathrm{~m}$ is 1.559 for the cable. The IFs in terms of angular displacements increase with braking effect varying from $0 \%$ to $29.32 \%$ and the average increment of the IFs is $124.31 \%$ at vehicle speed of $54 \mathrm{~km} / \mathrm{h}$.

Figure 18 shows the maximum of IF in terms of angular displacements at $72 \mathrm{~km} / \mathrm{h}$ vehicle speed and braking location from the left abutment at $13 \mathrm{~m}$ is 2.081 for the cable. The IFs in terms of angular displacements increase with braking effect varying from $0.8 \%$ to $20.64 \%$ and the average increment of the IFs is $10.07 \%$ at vehicle speed of $72 \mathrm{~km} / \mathrm{h}$.

In most cases, the IFs increase with the increments in vehicle speeds. The maximum value of the average IFs is 1.44 at the vehicle speed of $72 \mathrm{~km} / \mathrm{h}$ with braking effect in terms of element vertical deflection.

\section{Test Procedures}

3.1. The Studied Bridge. The Pho Nam bridge, a one lane bridge over the $\mathrm{Cu}$ De river, is shown in Figure 19. The steel cable-stayed bridge with double I-girder with the top reinforced concrete slab and diaphragms provides continuity over all three spans. 


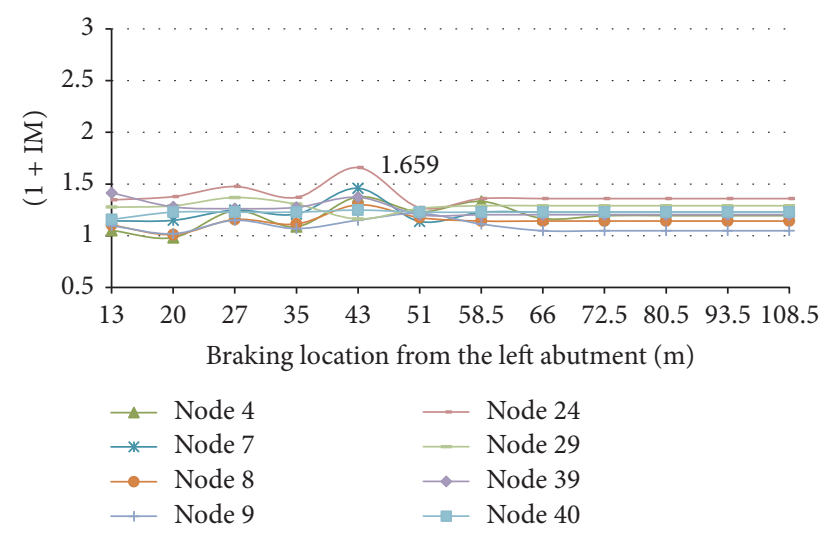

FIGURE 14: Variation of IF in terms of axial displacements at $72 \mathrm{~km} / \mathrm{h}$ vehicle speed considering braking.

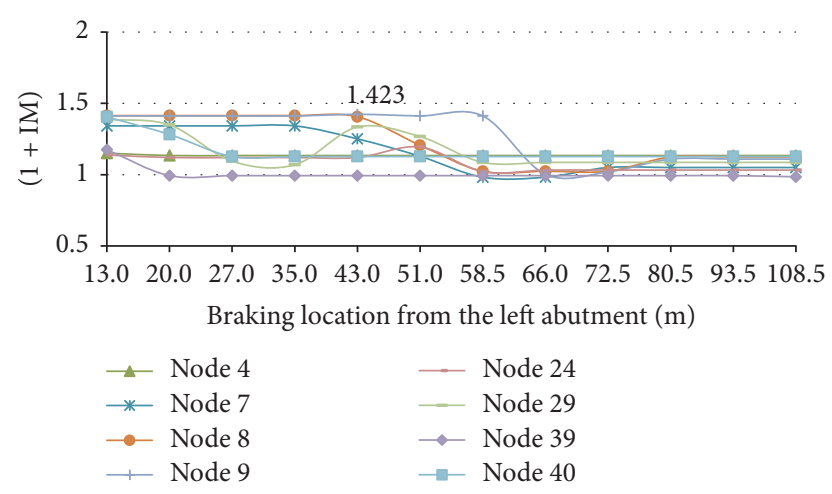

FIGURE 15: Variation of IF in terms of angular displacements at $18 \mathrm{~km} / \mathrm{h}$ vehicle speed considering braking.

3.2. Instrumentation. Instrumentation for measuring deflections was installed at specified locations prior to testing. The vertical deflections were measured, with linear variable displacement transducers (LVDTs), designed to provide displacement measurements. The LVDTs used for the dynamic tests were CDP-50 and CDP-100 gages manufactured by Tokyo Sokki Kenkyujo Co., Ltd., Japan, and shown in Figure 20. The gages were hanged on the under girder and the stayed cable (at points 1, 2, 3, and 4 as shown in Figures 19(b) and 19(c)) using a special steel wires developed by the research team. These particular LVDTs have a through-tube construction which allows a spring to be mounted at a fixed height under the core and tube. As the deflection occurs the spring will hold the tube at a fixed elevation and allow the core to move with the structure and along the tube. As the core moves through the tube, the voltage output changes. This voltage change can then be read with the data record system and converted to deflection.

3.3. Vehicle Testing. The test vehicle for the Pho Nam bridge is a KAMAZ-55111 dumper truck with three axles and the vehicle weight is $8560 \mathrm{~kg}$ with leaf spring suspension on the steering axle and the tandem rear axle (Figure 21). The test vehicle was driven over the bridge at speeds of $10 \mathrm{~km} / \mathrm{h}$, $15 \mathrm{~km} / \mathrm{h}, 20 \mathrm{~km} / \mathrm{h}, 25 \mathrm{~km} / \mathrm{h}, 30 \mathrm{~km} / \mathrm{h}, 35 \mathrm{~km} / \mathrm{h}$, and $40 \mathrm{~km} / \mathrm{h}$,

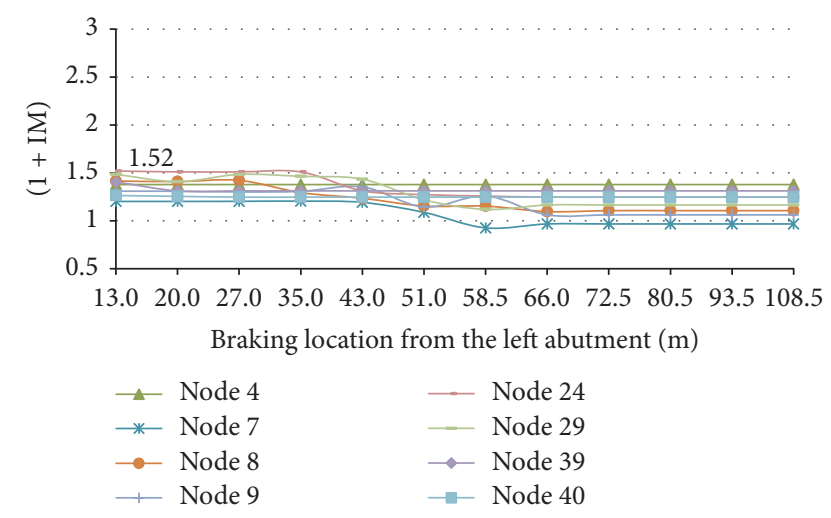

FIGURE 16: Variation of IF in terms of angular displacements at $36 \mathrm{~km} / \mathrm{h}$ vehicle speed considering braking.

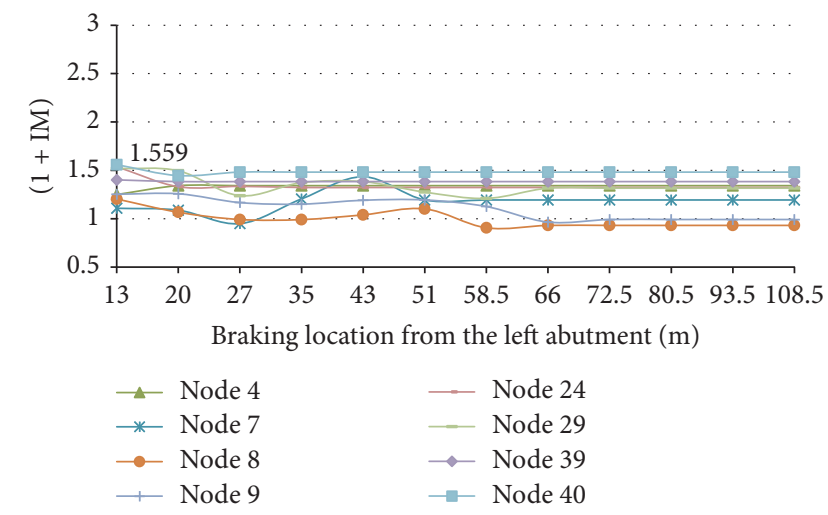

FIGURE 17: Variation of IF in terms of angular displacements at $54 \mathrm{~km} / \mathrm{h}$ vehicle speed considering braking.

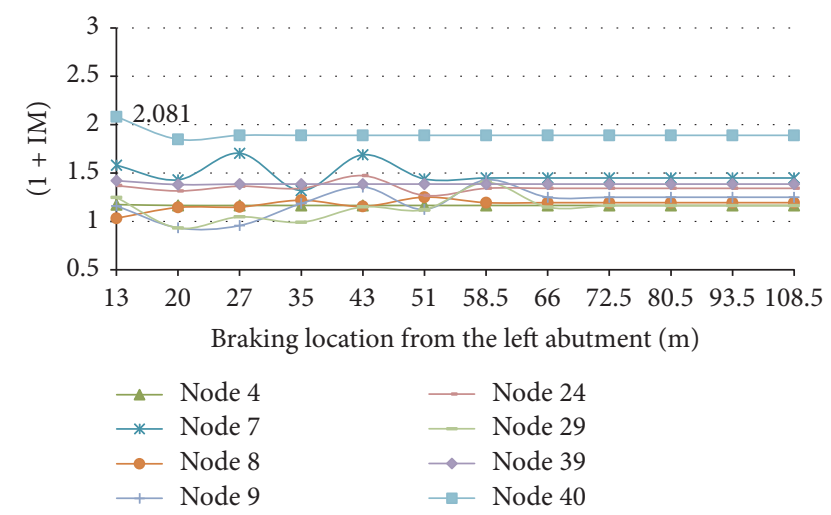

FIGURE 18: Variation of IF in terms of angular displacements at $72 \mathrm{~km} / \mathrm{h}$ vehicle speed considering braking.

braking at positions $1 / 4,1 / 2$, and $3 / 4$ of the left side span for the Pho Nam bridge.

\section{Results and Discussions}

The experimental results of IFs at points $1,2,3$, and 4 on the Pho Nam bridge (Figure 19(b)), with velocity at sudden braking are $10 \mathrm{~km} / \mathrm{h}, 15 \mathrm{~km} / \mathrm{h}, 20 \mathrm{~km} / \mathrm{h}, 25 \mathrm{~km} / \mathrm{h}, 30 \mathrm{~km} / \mathrm{h}$, 


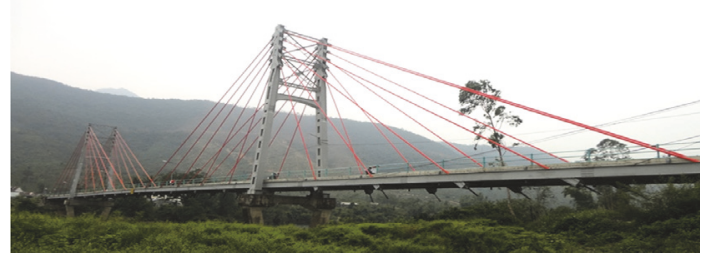

(a) Pho Nam bridge

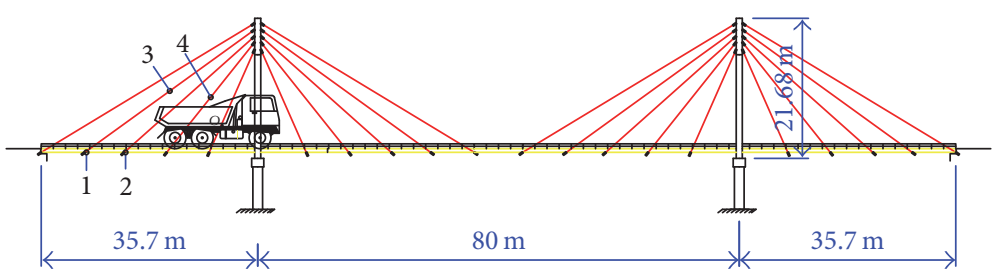

(b) Elevation plan

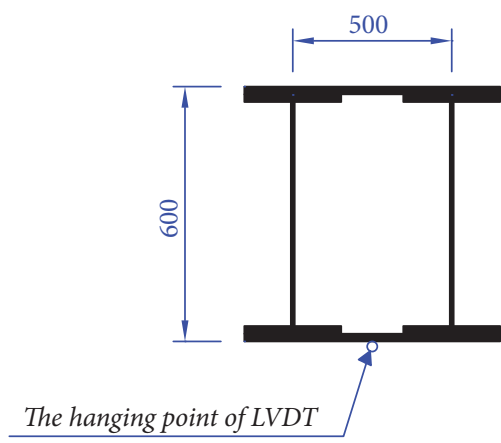

(c) Cross-section of double I-girder

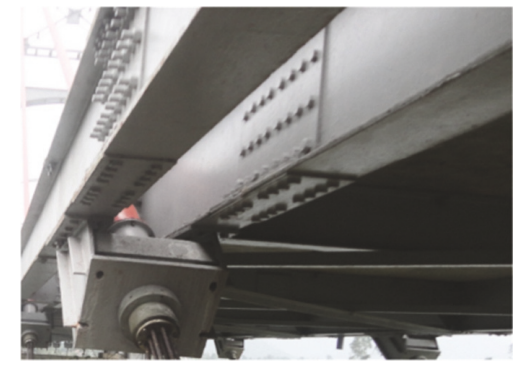

All dimensions in ( $\mathrm{mm})$

Figure 19: Detail of the Pho Nam bridge.

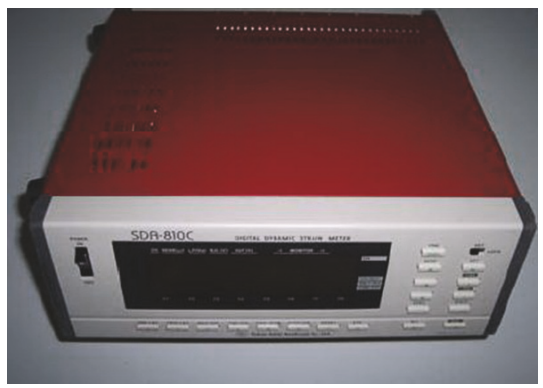

(a) The data record system

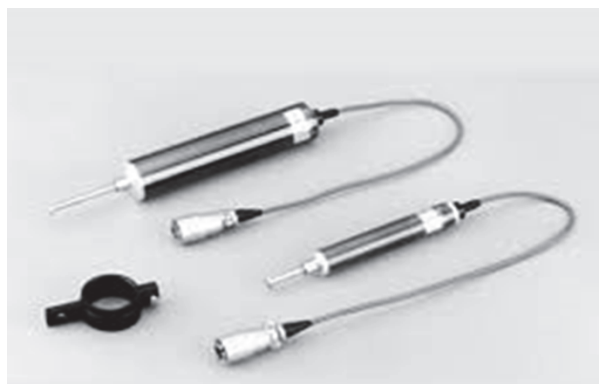

(b) CDP-50 and CDP-100 displacement transducer

Figure 20: The instruments of testing.

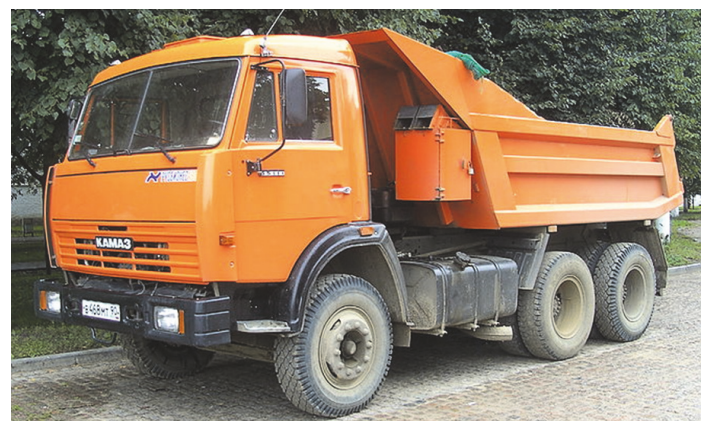

Figure 21: The KAMAZ-55111 dumper truck.

$35 \mathrm{~km} / \mathrm{h}$, and $40 \mathrm{~km} / \mathrm{h}$, respectively, and are shown in Figures 22 and 23. The larger velocity has not been tested because safe conditions were not allowed.
Through experimental results and FEM analysis of IFs at positions 1, 2, 3, and 4 of the Pho Nam bridge shown in Figures 22 and 23, the authors have following comments:

(i) The uptrend and the downtrend of the IFs are found in experimental investigation and FEM analysis is similarity.

(ii) In velocity range of $10-40 \mathrm{~km} / \mathrm{h}$, the IF increases with an increase in velocity at sudden braking; the variations of IF with velocity at sudden braking are shown in Figures 22(a)-22(e).

(iii) In the limits of velocity, the IF decreases with increasing the distance from the bearing location; the variations of IF with braking positions are shown in Figures 23(a)-23(h). 


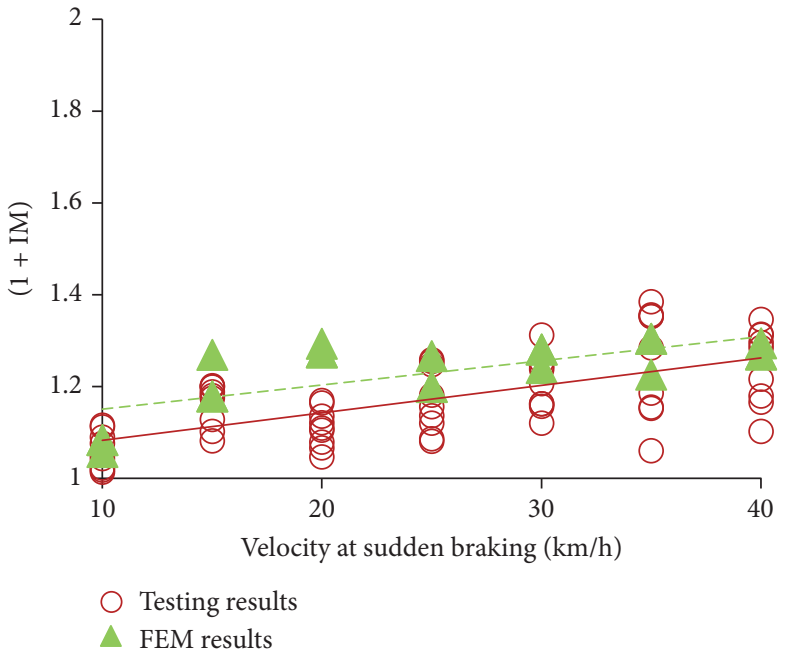

(a) IF versus velocity, sudden braking at point 1

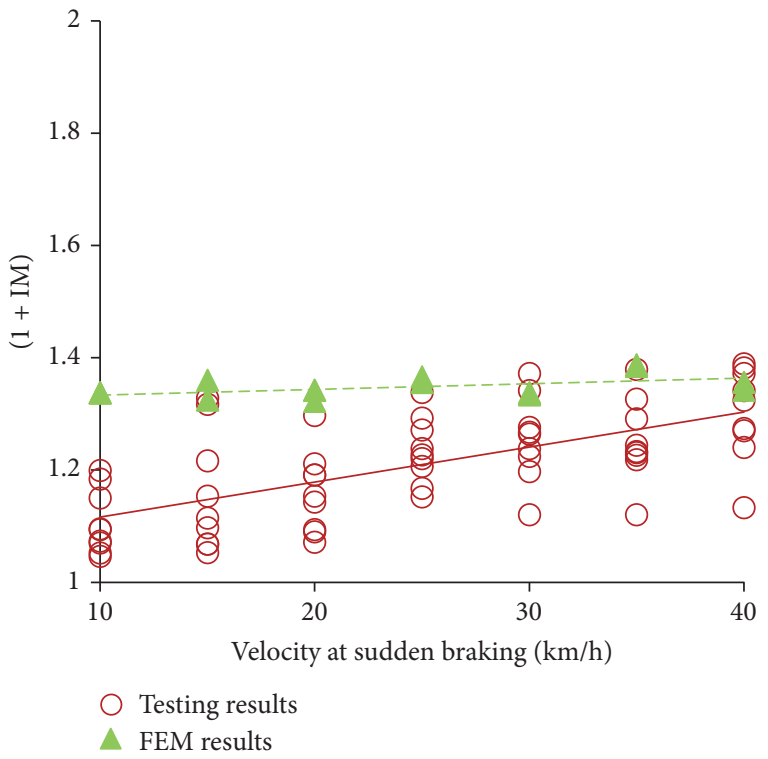

(c) IF versus velocity, sudden braking at point 3

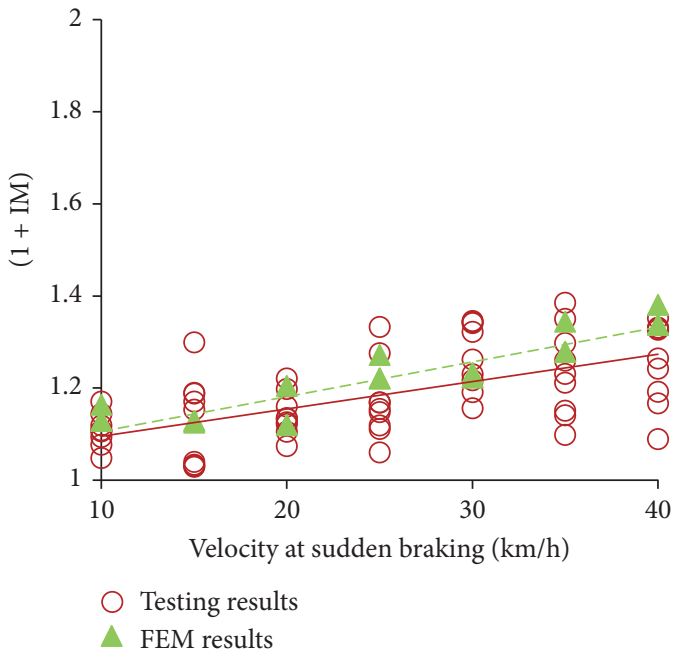

(b) IF versus velocity, sudden braking at point 2

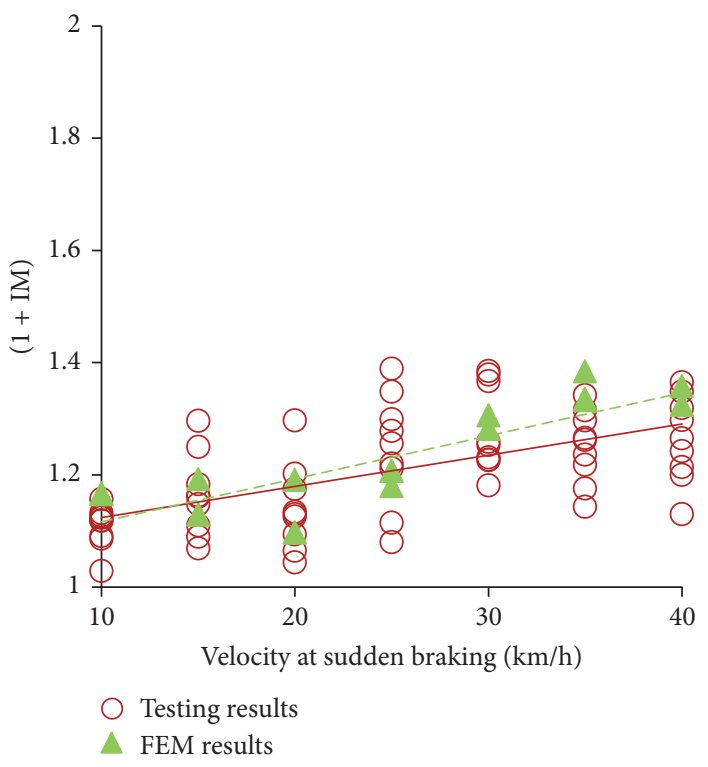

(d) IF versus velocity, sudden braking at point 4

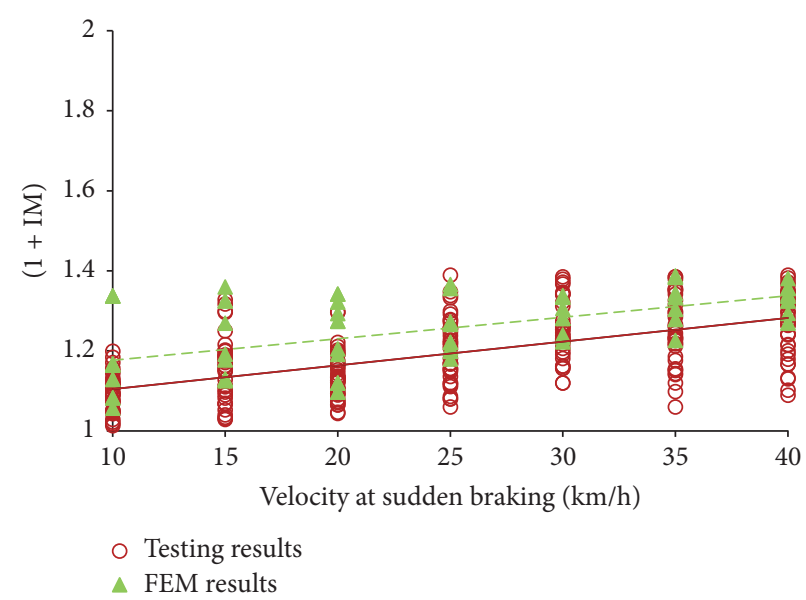

(e) IF versus velocity, sudden braking at all points 1, 2, 3, and 4

FIGURE 22: IF versus velocity at sudden braking. 

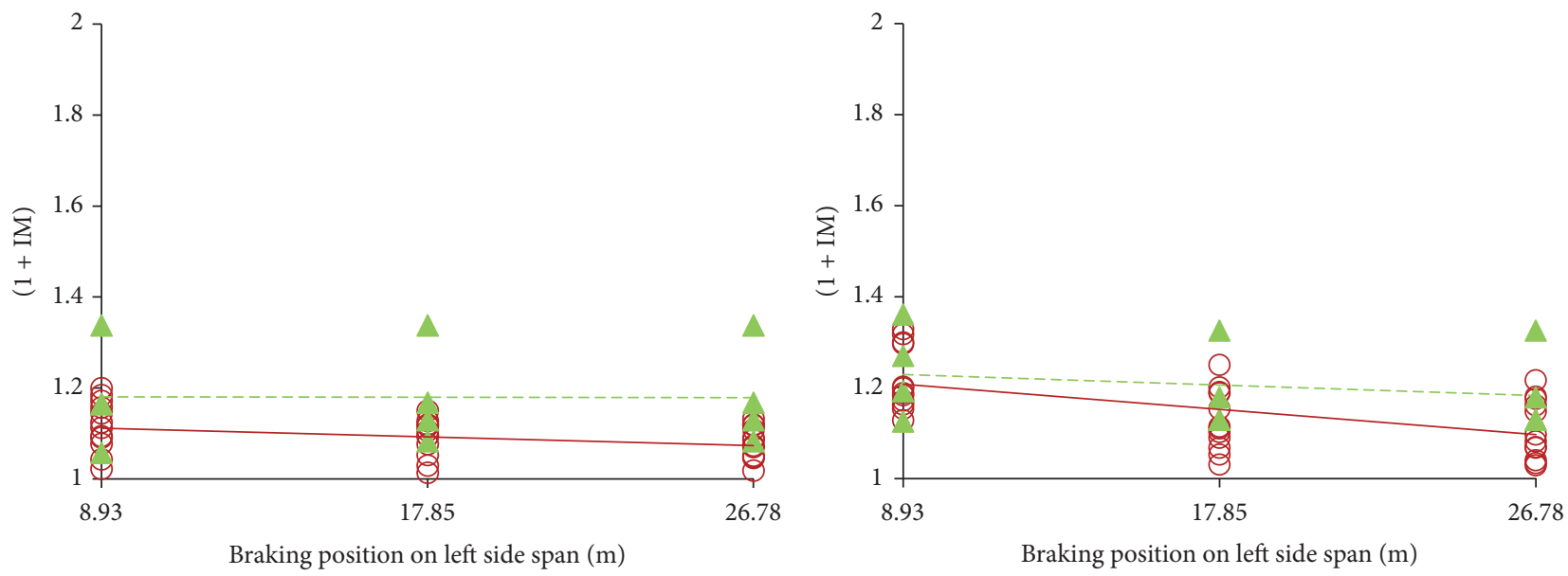

$\bigcirc$ Testing results

$\triangle$ FEM results

○ Testing results

$\triangle$ FEM results

(a) IF versus braking position, $V=10 \mathrm{~km} / \mathrm{h}$

(b) IF versus braking position, $V=15 \mathrm{~km} / \mathrm{h}$
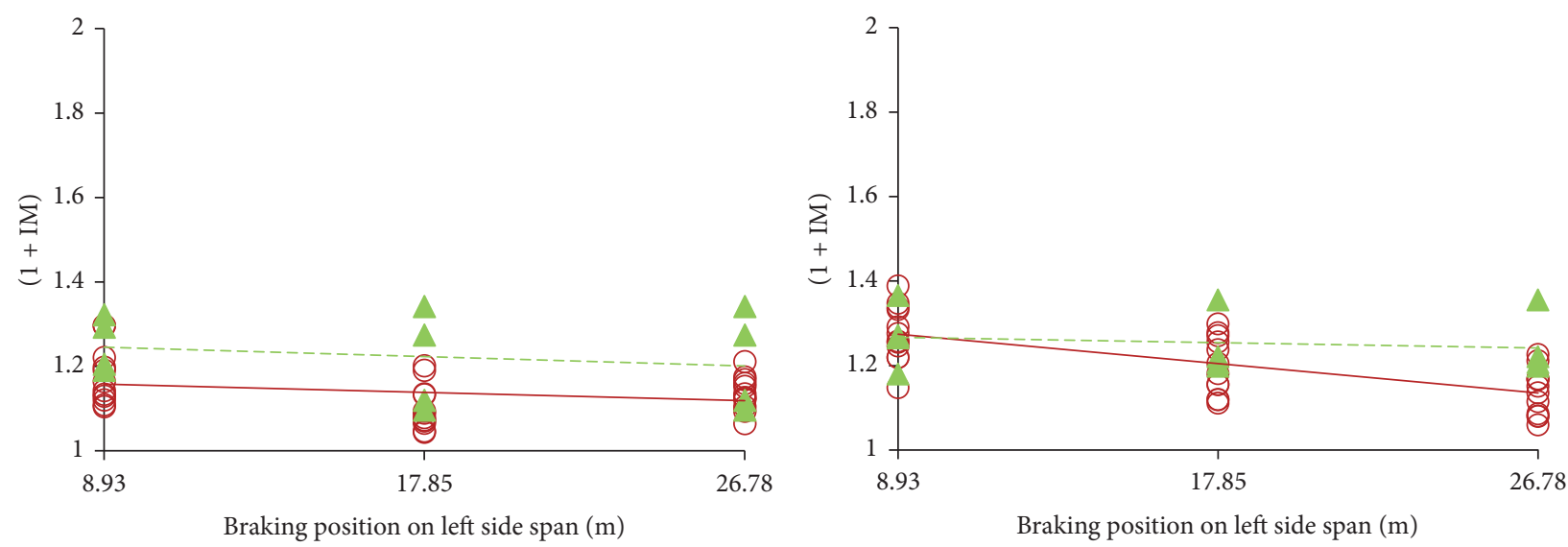

O Testing results

FEM results

(c) IF versus braking position, $V=20 \mathrm{~km} / \mathrm{h}$

$\bigcirc$ Testing results

$\triangle$ FEM results

(d) IF versus braking position, $V=25 \mathrm{~km} / \mathrm{h}$
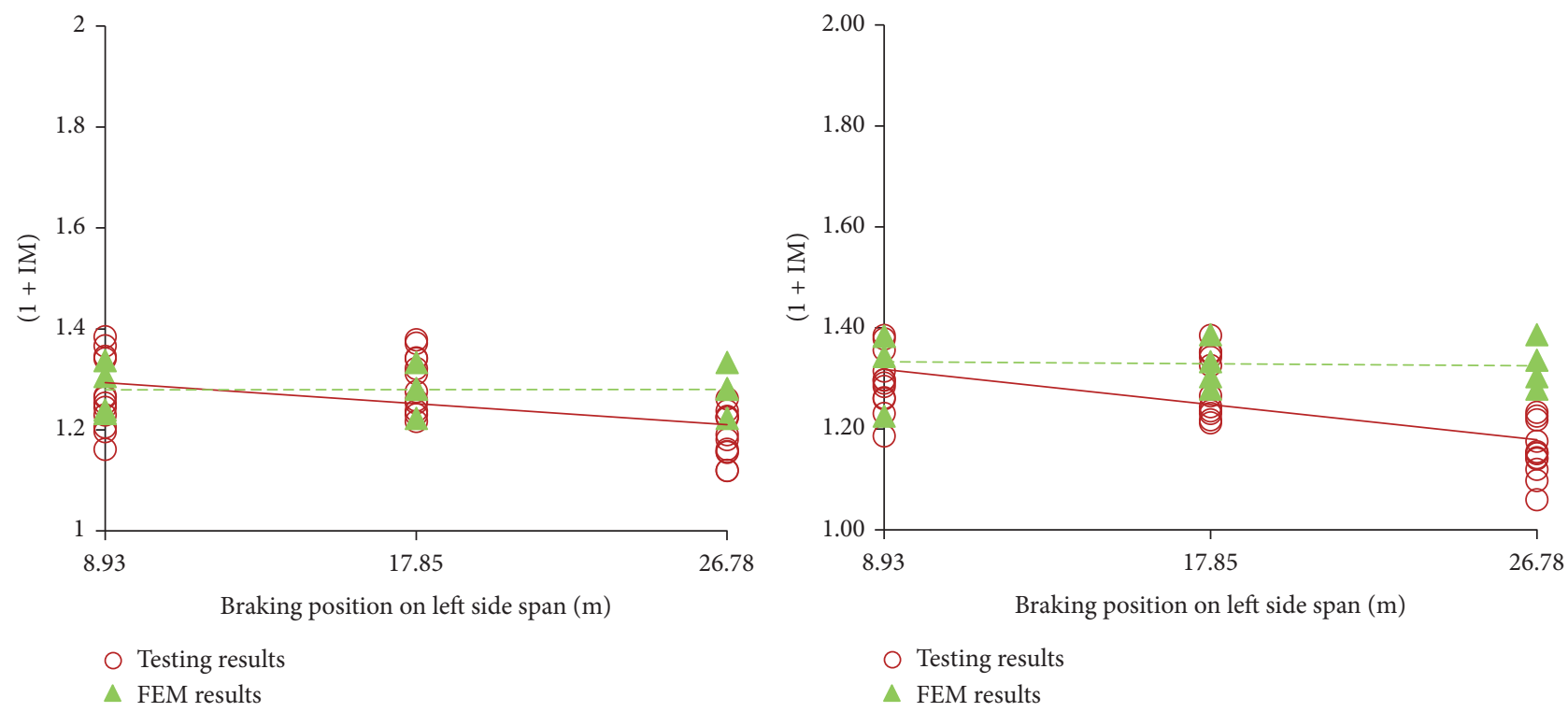

Testing results

$\triangle$ FEM results

(e) IF versus braking position, $V=30 \mathrm{~km} / \mathrm{h}$

(f) IF versus braking position, $V=35 \mathrm{~km} / \mathrm{h}$

Figure 23: Continued. 


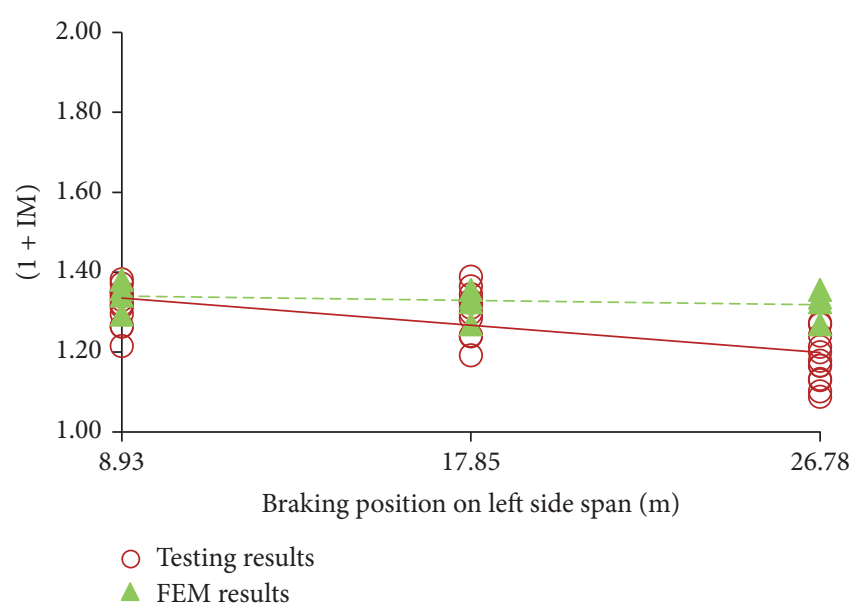

(g) IF versus braking position, $V=40 \mathrm{~km} / \mathrm{h}$

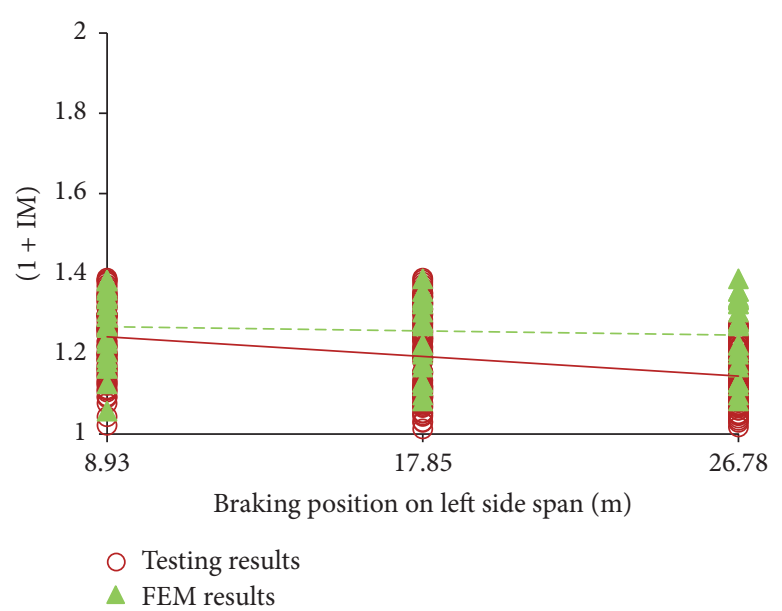

(h) IF versus braking position, $V=10-40 \mathrm{~km} / \mathrm{h}$

FIGURE 23: IF versus braking position.

\section{Conclusions}

In this paper, the FEM is used to investigate the dynamic response of CSB due to a three-axle vehicle considering braking effects. The overall findings with higher vehicle speed offer to take a standard IF or $(1+$ IM) more than 1.44 for cable-stayed bridge and recommend about 30\% for maximum impacted increment over IF results calculated in terms of vertical deflections, axial displacements, and angular displacements considering braking effects.

In addition, the impact factors are investigated on both FEM analysis and experiment study on the Pho Nam bridge. In velocity range of $10-40 \mathrm{~km} / \mathrm{h}$, the IF increases with an increase in velocity at sudden braking and the IF decreases with increasing the distance from the bearing location. Accordingly, the authors recommend that in bridge design, engineers should take into account the dynamic interaction caused by the vehicle moving on bridge and the sudden braking.

\section{Conflicts of Interest}

The authors declare that there are no conflicts of interest regarding the publication of this article.

\section{Acknowledgments}

The research described in this paper was financially supported by the fund for scientific research of Vietnam's Ministry of Education and Training.

\section{References}

[1] L. Fryba, "Quasi-static distribution of braking and starting forces in rails and bridge," Rail International, vol. 5, no. 11, pp. 698-716, 1974.

[2] H. Kishan and R. W. Trail-Nash, "A modal method for calculation of highway bridge response with vehicle braking," Civil
Engineering Transactions, Institution of Engineers, Australia, vol. 19, no. 1, pp. 44-50, 1977.

[3] R. K. Gupta and R. W. Trail-Nash, "Bridge dynamic loading due to road surface irregularities and braking of vehicle," Earthquake Engineering \& Structural Dynamics, vol. 8, no. 2, pp. 83-96, 1980.

[4] S. S. Law and X. Q. Zhu, "Bridge dynamic responses due to road surface roughness and braking of vehicle," Journal of Sound and Vibration, vol. 282, no. 3-5, pp. 805-830, 2005.

[5] S.-H. Ju and H.-T. Lin, "A finite element model of vehicle-bridge interaction considering braking and acceleration," Journal of Sound and Vibration, vol. 303, no. 1-2, pp. 46-57, 2007.

[6] A. González, "Vehicle-bridge dynamic interaction using finite element modelling," in Finite Element Analysis, pp. 637-662, Sciyo, Rijeka, Croatia, 2010.

[7] L. Deng and C. S. Cai, "Development of dynamic impact factor for performance evaluation of existing multi-girder concrete bridges," Engineering Structures, vol. 32, no. 1, pp. 21-31, 2010.

[8] X. Yin, Z. Fang, C. S. Cai, and L. Deng, "Non-stationary random vibration of bridges under vehicles with variable speed," Engineering Structures, vol. 32, no. 8, pp. 2166-2174, 2010.

[9] H. Zhang and X. Xie, "Dynamic responses of cable-stayed bridges to vehicular loading including the effects of the local vibration of cables," Journal of Zhejiang University-Science A: Applied Physics \& Engineering, vol. 12, no. 8, pp. 593-604, 2011.

[10] Y. Zhou, Z. J. Ma, Y. Zhao, X. Shi, and S. He, "Improved definition of dynamic load allowance factor for highway bridges," Structural Engineering and Mechanics, vol. 54, no. 3, pp. 561-577, 2015.

[11] L. Deng and F. Wang, "Impact factors of simply supported prestressed concrete girder bridges due to vehicle braking," Journal of Bridge Engineering, vol. 20, no. 11, Article ID 06015002, 2015.

[12] X. N. Toan and V. T. Duc, "A finite element model of vehicle-cable stayed bridge interaction considering braking and acceleration," in Proceedings of the World Congress on Advances in Civil, Environmental, and Materials Research, Busan, Korea, August 2014.

[13] X. N. Toan and V. T. Duc, "Vehicle-cable stayed bridge dynamic interaction considering the vehicle braking effects using the 
finite element method," in Proceedings of the 16th Asia Pacific Vibration Conference, Hanoi, Vietnam, November 2015.

[14] N. X. Toan, "Dynamic interaction between the two-axle vehicle and continuous girder bridge with considering vehicle braking force," in Proceedings of the 16th Asia Pacific Vibration Conference, vol. 36, Hanoi, Vietnam, November 2015.

[15] X. Nguyen, V. Tran, and N. Hoang, "A Study on the dynamic interaction between three-axle vehicle and continuous girder bridge with consideration of braking effects," Journal of Construction Engineering, vol. 2017, Article ID 9293239, 12 pages, 2017.

[16] AASHTO LRFD, Bridge Design Specifications, American Association of State Highway and Transportation Officials, Washington, Wash, USA, 6th edition, 2012.

[17] O. C. Zienkiewicz and R. L. Taylor, The Finite Element Method: Its Basis and Fundamentals, Butterworth-Heinemann, Oxford, UK, 5th edition, 2000.

[18] T. Shimada, "Estimating method of cable tension from natural frequency of high mode," Doboku Gakkai Ronbunshu, vol. 1-29, no. 501, pp. 163-171, 1994.

[19] W. C. Ray and P. Joseph, Dynamics of Structures, Computers \& Structures, Berkeley, CA, USA, 3rd edition, 2003. 


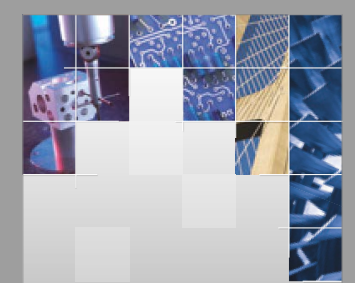

\section{Enfincering}
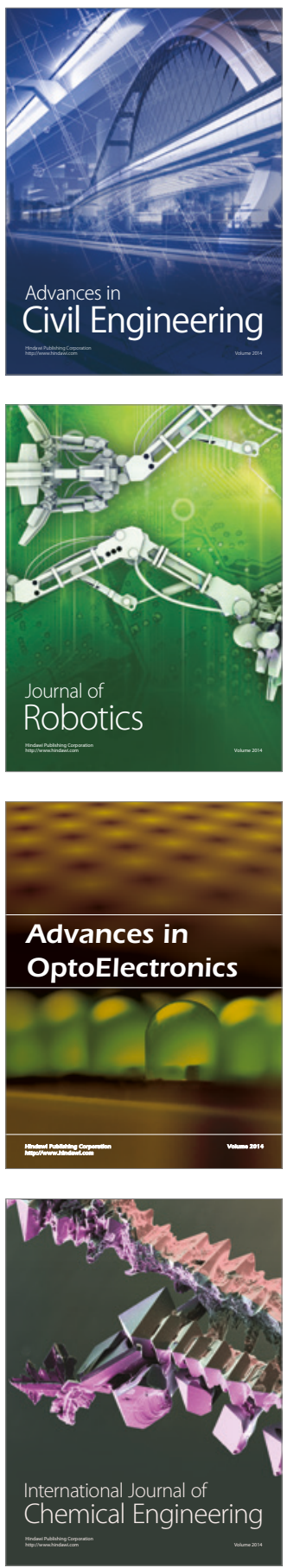

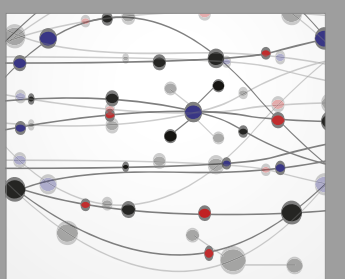

The Scientific World Journal

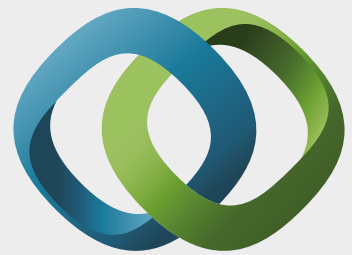

\section{Hindawi}

Submit your manuscripts at

https://www.hindawi.com
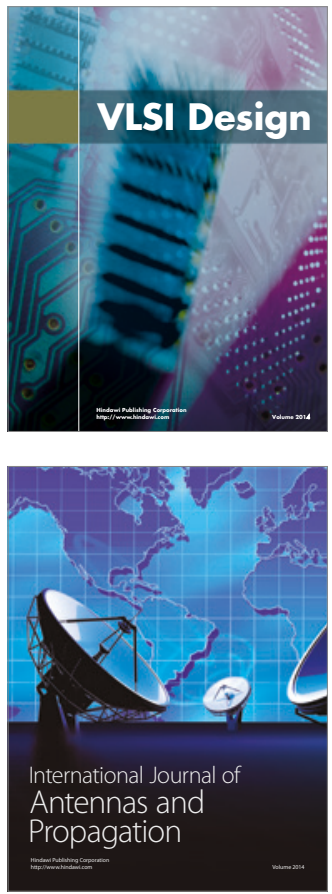

\section{Rotating}

Machinery
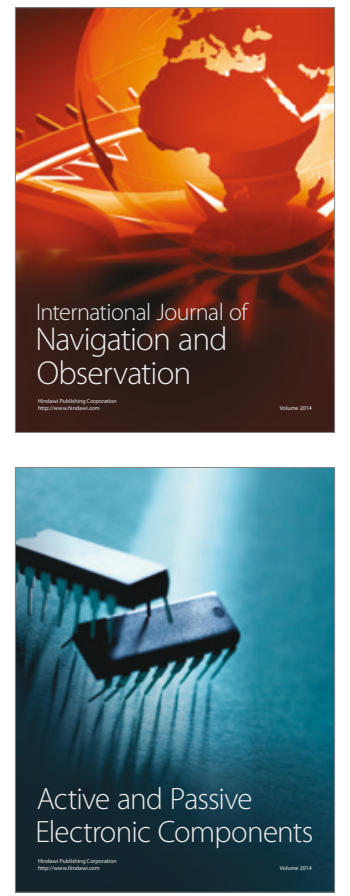
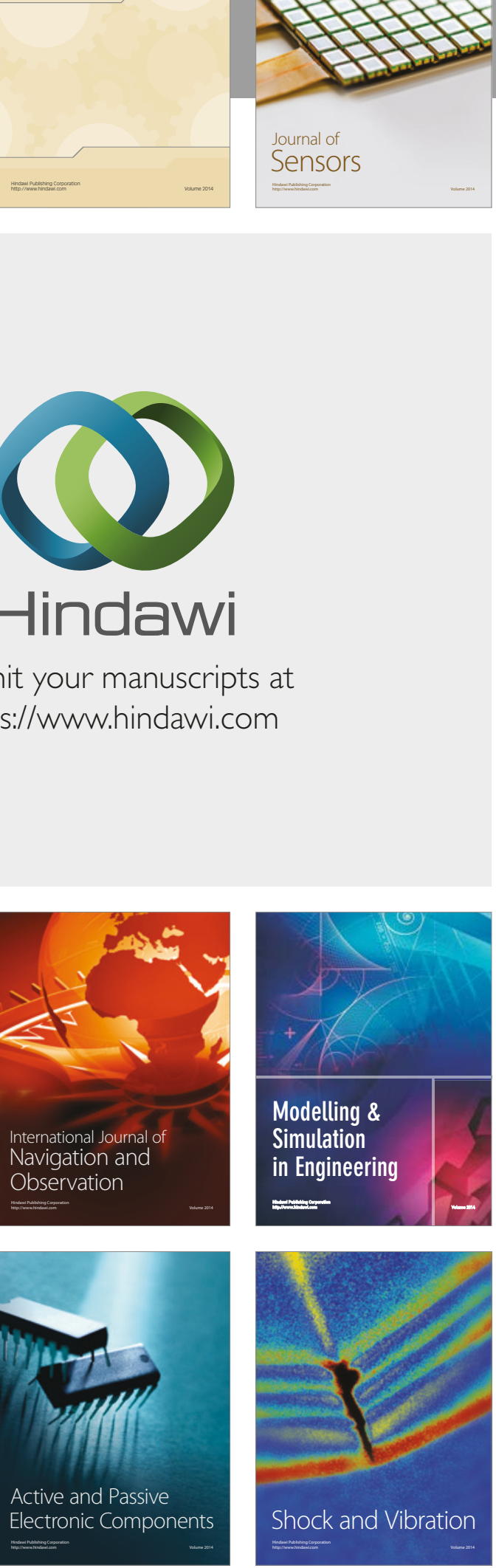
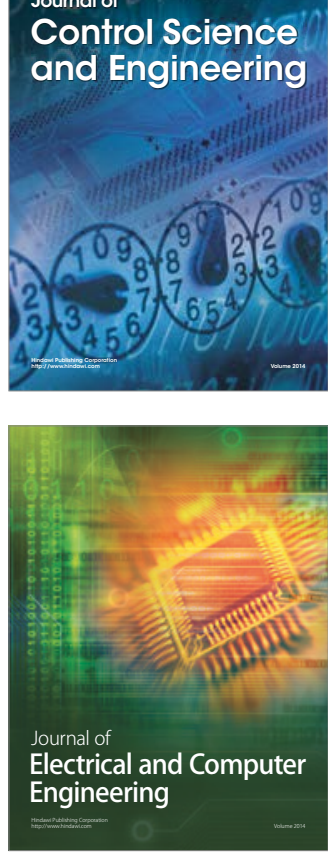

Distributed

Journal of

Control Science

and Engineering
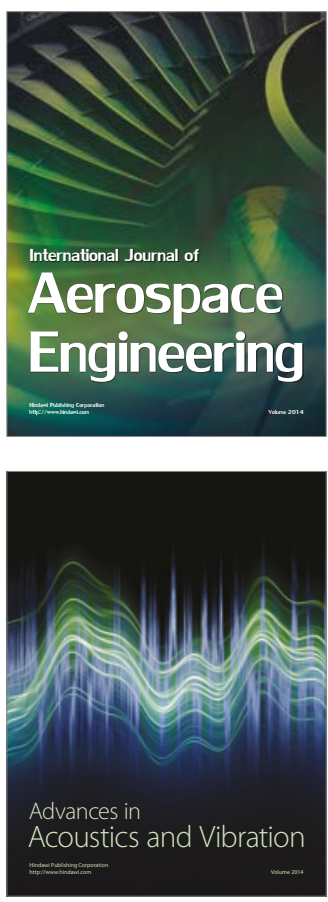

Sensor Networks 